http://ejournal.upi.edu/index.php/jaz - e-mail: jurnal.zonasi@gmail.com dan jurnal_zonasi@upi.edu doi.org/10.17509/jaz.v3i1.19262

\title{
Kajian Arsitektur terhadap Analisa Perilaku pada Bangunan Perumahan Citra Grand City Palembang
}

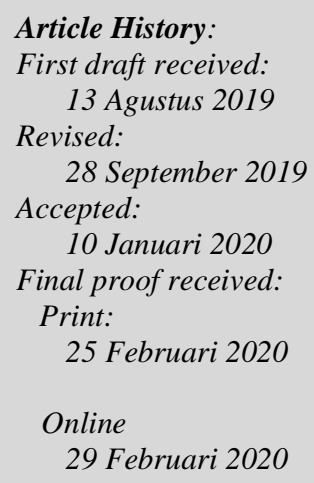

\author{
J.M. Sri Narhadi \\ Universitas Katolik Musi Charitas, Palembang, Indonesia \\ Jalan Bangau No. 60 Palembang \\ Email: narhadi@ukmc.ac.id
}

\begin{abstract}
Housing in urban areas has become a necessity both in terms of current housing needs and future housing needs. All of these housing developments have their own targets in meeting their needs. The government itself also targets that the existing housing can be reached by all levels of society.

Citra Grand City Palembang is an example of an elite residential complex in Palembang and was developed since 2008. Citra Grand City is designed as a city that has good accessibility. With its status as a residential complex of elite complexes, it is interesting to study how the behavior contained therein is reviewed through architectural rules. In connection with the field of architecture the behavior to be observed is the garbage disposal system, parking arrangement, compliance with building boundary rules, and aesthetic observation.
\end{abstract}

Keywords: Housing, Architecture, Behavior

\begin{abstract}
Abstrak: Perumahan dalam perkotaan saat ini telah menjadi sebuah kebutuhan baik ditinjau dari kebutuhan rumah saat ini maupun kebutuhan rumah akan datang. Kesemua pembangunan perumahan ini mempunyai target tersendiri dalam pemenuhan kebutuhannya. Pemerintah sendiri juga menargetkan agar perumahan yang ada saat ini dapat dijangkau oleh semua lapisan masyarakat.

Citra Grand City Palembang adalah sebuah contoh bangunan perumahan kompleks elite yang ada di Palembang dan dikembangkan sejak tahun 2008. Citra Grand City dirancang sebagai kota yang memiliki aksesibilitas yang baik. Dengan statusnya sebagai sebuah kawasan bangunan perumahan kompleks elite, menarik untuk dikaji bagaimana perilaku yang terdapat di dalamnya ditinjau melalui kaidah arsitektur. Dalam kaitan dengan bidang arsitektur perilaku yang akan diamati adalah sistem pembuangan sampah, penataan parkir, kepatuhan terhadap aturan garis sempadan bangunan, dan observasi estetika.

Kata Kunci: Perumahan, Arsitektur, Perilaku
\end{abstract}

\section{Pendahuluan}

Rumah atau tempat tinggal merupakan kebutuhan dasar setiap manusia (Pindo Tutuko, 2008). Pembangunan perumahan di perkotaan sekarang ini juga boleh dikatakan sangat pesat. Perumahan dalam perkotaan saat ini telah menjadi sebuah kebutuhan baik ditinjau dari kebutuhan rumah saat ini maupun kebutuhan rumah akan dating (Susanti, Komala Dewi, dan Permana, 2018). Kebutuhan akan Perumahan Kota dapat ditinjau dari beberapa aspek (Hamzah F. Rachman, 2010) yaitu :

- Jumlah dan kepadatan penduduk

- Jumlah rumah layak huni

- Luas kota

- Sosial ekonomi penduduk

Dalam pembangunan perumahan terdapat 3 kelas (Muhamad Afdi Nizar, 2015) yaitu :

1. Perumahan untuk golongan bawah

2. Perumahan untuk golongan menengah

3. Perumahan untuk golongan atas 
Kesemua pembangunan perumahan ini mempunyai target tersendiri dalam pemenuhan kebutuhannya. Pemerintah sendiri juga menargetkan agar perumahan yang ada saat ini dapat dijangkau oleh semua lapisan masyarakat (Nadiar, Azmi, dan Nusantara, 2019).

Di antara ke 3 golongan perumahan yang dibangun, perumahan untuk golongan atas atau perumahan elite belum terlalu marak pelaksanaannya. Perumahan elite ini pastinya memiliki keunggulan - keunggulan sehingga dikatakan elite. Baik dari segi kawasan, fasilitas, sarana dan prasarana serta lingkungan hidup yang tercipta harus menjadi perhatian utama dalam pembangunan perumahan elite ini. Citra Grand City Palembang adalah sebuah contoh bangunan perumahan kompleks elite yang ada di Palembang dan dikembangkan sejak tahun 2008.

Citra Grand City dirancang sebagai kota yang memiliki aksesibilitas yang baik. Untuk itu saat ini sedang dilakukan penyelesaian jalan boulevard untuk tembus ke Jalan Soekarno Hatta. Penyelesaian jalan boulevard hingga tembus ke jalan Soekarno Hatta akan memberikan akses yang sangat mudah bagi penghuni dan pelaku usaha di kawasan Citra Grand City. Nantinya untuk menuju keluar dari kawasan ini tidak perlu memutar melalui Jalan Alang-Alang Lebar tetapi bisa melalui jalan boulevard yang tembus ini menuju ke jalan Soekarno Hatta dan terus ke wilayah lain.

Dengan statusnya sebagai sebuah kawasan bangunan perumahan kompleks elite, menarik untuk dikaji bagaimana perilaku yang terdapat di dalamnya ditinjau melalui kaidah arsitektur. Dalam kaitan dengan bidang arsitektur perilaku yang akan diamati adalah sistem pembuangan sampah, penataan parkir, kepatuhan terhadap aturan garis sempadan bangunan, dan observasi estetika.

\section{Permasalahan}

- Bagaimana sistem pembuangan sampah yang dilakukan terhadap kompleks perumahan sehingga kebersihan tetap terjaga.

- Bagaimana penataan parkir di dalam kompleks perumahan

- Apakah bangunan pada bangunan kompleks telah memenuhi persyaratan gsb

- Observasi terhadap estetika pada perumahan kompleks

\section{Metode Penelitian}

Metode penelitian yang digunakan pada penelitian ini meliputi: metode survei (pengamatan langsung) dan analisa, metode wawancara yang dilakukan dengan pihak penghuni kompleks, pengunjung maupun pengelola kompleks perumahan Citra Grand City Palembang, serta metode kepustakaan dengan studi literatur melalui buku dan mengakses internet mengenai semua teori yang berhubungan dengan perumusan masalah.

\section{Hasil dan Pembahasan}

\subsection{Sekilas Profil Ciputra Group}

Ciputra Residence adalah anak perusahaan dari Grup Ciputra, salah satu pengembang properti terbesar di Indonesia dengan fokus pengembangan skala kota serta mixed-use development. Ciputra Residence dikenal atas portfolio pemukiman yang ternama serta standar tinggi dan integritas perusahaan. Perusahaan ini tersebar secara geografis di berbagai lokasi di Indonesia. Proyek pertamanya adalah CitraGarden City yang berlokasi dekat dengan Bandar Udara Internasional Soekarno Hatta yang dikembangkan pada tahun 1989. Selanjutnya pada tahun 1994, Ciputra Residence mengembangkan kota mandiri CitraRaya, yang juga merupakan proyek terbesar di dalam Grup Ciputra. Semenjak itu Ciputra Residence sudah memulai proyek di kota-kota lain di Jawa, Sumatra dan Kalimantan.

Mulai tahun 2013 Ciputra Residence mulai menggarap proyek mixed use dan high-rise, dimulai dengan apartemen Citra Lake Suites. Dilanjut oleh proyek apartemen dan perkantoran lainnya di daerah Puri dan Kemayoran. Sebagai pengembang kawasan perumahan terpadu yang terkemuka, Ciputra Residence mendapat keuntungan skala ekonomis yang memungkinkan efisiensi biaya dari kontrak-kontrak pembangunan. Perseroan juga dapat menikmati harga jual yang lebih tinggi dengan adanya kepedulian atas produk yang balk. Saat ini Perseroan menaungi 13 (tiga belas) Entitas Anak, 14 (empat belas) Entitas Asosiasi dan 2 (dua) Entitas Joint Venture. Berbekal lebih dari 24 tahun pengalaman di sektor properti dan dengan tingkat dedikasi dan integrasi yang tinggi, Ciputra Residence memiliki Iandasan yang kuat untuk menjadi pengembang berkualitas dalam menggarap pasar properti di Indonesia. 


\section{Pengenalan Kompleks Citra Grand City Palembang}

CitraGrand City Palembang merupakan kawasan kota terpadu yang dibangun di atas lahan seluas 250 HA yang saling terintegrasi antara hunian, ruang komersil dan beragam fasilitas seperti Amanzi WaterPark, sekolah, fasilitas ibadah, system keamanan 24 jam, children playground, dll. Seiring perkembangan, CitraGrand City yang terletak di area Sunrise Property (Kawasan Talang Kelapa) telah menjadi salah satu lokasi investasi terbaik bagi masyrakat kota Palembang dengan akses hanya 10 menit menuju International Airport dan 7 menit menuju LRT. Lebih dari sekedar menghadirkan sebuah kawasan hunian yang nyaman bagi para penghuninya, CitraGrand City memiliki misi untuk meningkatkan level of happiness para penghuninya melalui konsep pembangunan ramah lingkungan (EcoCulture). Dengan menghadirkan beragam kegiatan dan komunitas bertemakan EcoCulture, CitraGrand City kini menjadi salah satu kota terpadu terbaik dan terbesar di kota Palembang.

\subsection{Pembahasan Cluster Tropical Valley}

Tropical Valley merupakan cluster tingkat menegah, dalam cluster Tropical Valley ini menggunakan konsep Eco Culture yang pada konsep ini mengutamakan aspek penataan lansekap yang berfungsi sebagai penyeimbang ekologi, memberikan keteduhan, mempercantik lingkungan dan memberikan kualitas udara yang lebih sehat. Citra Grand City menggunakan konsep Eco Culture di setiap perumahan yang di bangun oleh Citra Grand City, letak cluster Tropical Valley ada di bagian tahap II pembangunan Citra Grand City.

\section{Jenis-Jenis rumah di Tropical Valley}

Tropical Valley memiliki 7 jenis fasad rumah yang menggunakan pendekatan fasad minimalis di bangunan tersebut, jenis jenis fasad tersebut berupa Alamanda, Amarilis, Azalea, Banyan, Bismarkia, Bromelia, Burgundy. Nama dari jenis rumah ini di ambil dari nama tanaman yang identik dengan tanaman tropis.

Tampilan fasad yang minimalis ini membuat penampakan bangunan hunian yang terdapat di sana memiliki kesan modern dan berkelas. Permainan warna dari masing-masing bangunan juga memberikan efek bahwa perumahan yang ada di sana bukanlah perumahan yang biasa-biasa saja.

\section{Gerbang Cluster}

Gerbang cluster menggunakan jenis portal, dan arus keluar masuk dalam perumahan ini di lakukan dengan satu jalur.

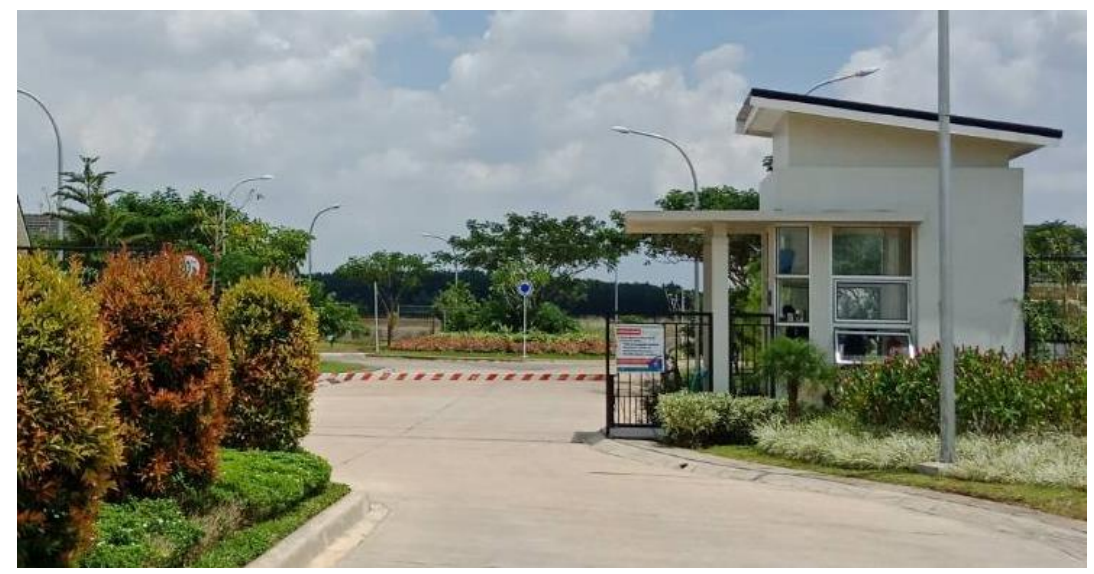

Gambar 1. Gerbang Cluster Tropical Valley

Sumber: Pribadi

Jaringan Listrik

Jaringan listrik di dalam perumahan Tropical Valley menggunakan sistem tanam di dalam tanah. Gardu listrik berada diluar site cluster. 


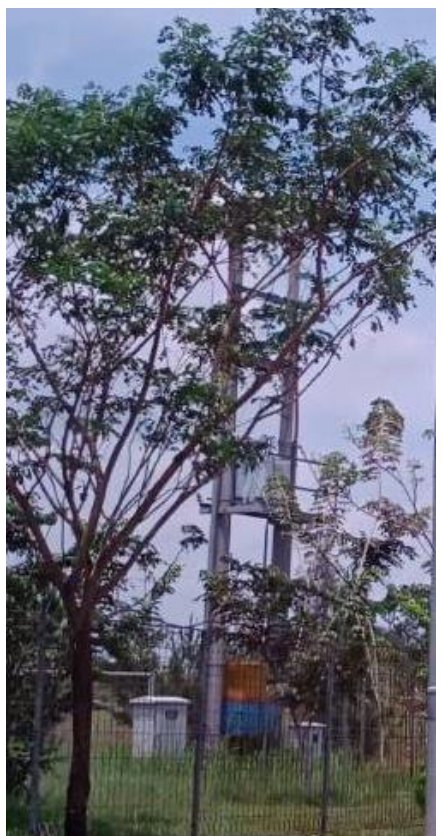

Gambar 2. Gardu cluster Tropical Valley Sumber: Pribadi

Kemudian dari gardu listrik baru di alirkan ke rumah masing-masing.

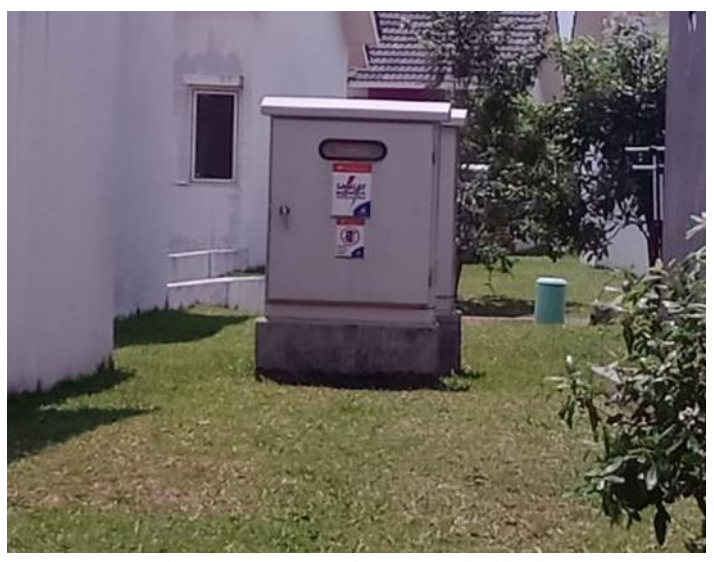

Gambar 3. Electric panel di cluster

Sumber: Pribadi

Di dalam perumahan ini juga dilengkapi genset sebagai tenaga cadangan dalam keadaan listrik padam.

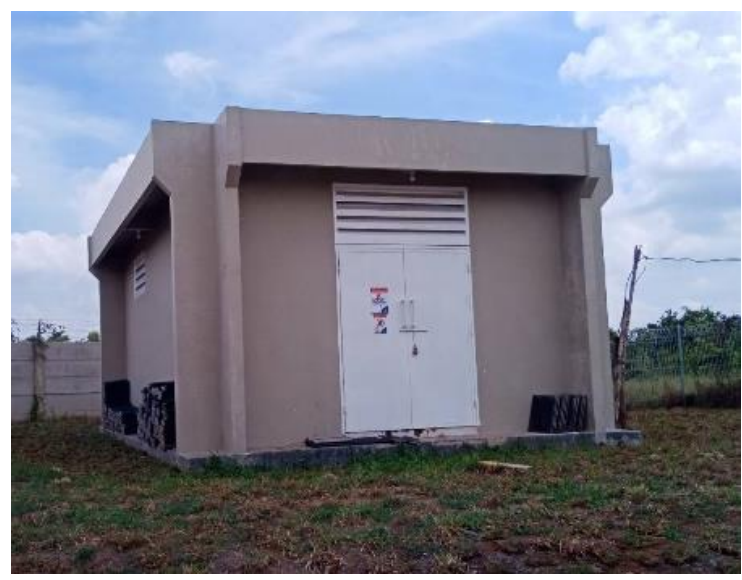

Gambar 4. Ruang genset di Tropical Valley Sumber: Pribadi 
Jaringan Air Bersih

Penyediaan air bersih di dalam cluster Tropical Valley menggunakan air dari PDAM

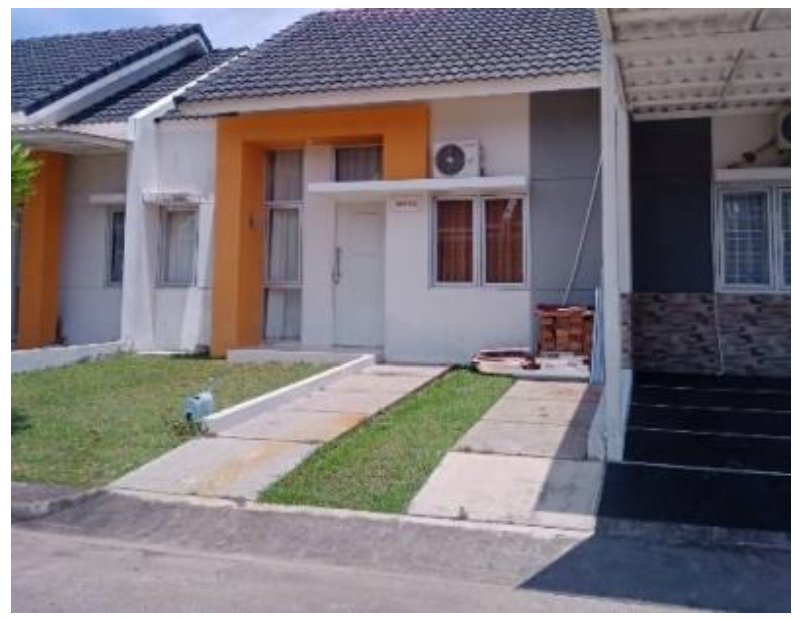

Gambar 5. Meteran PDAM

Sumber: Pribadi

Jaringan Air Kotor

Jaringan air kotor yang ada di cluster Tropical Valley menggunakan riol kota yang di tutup dengan beton.

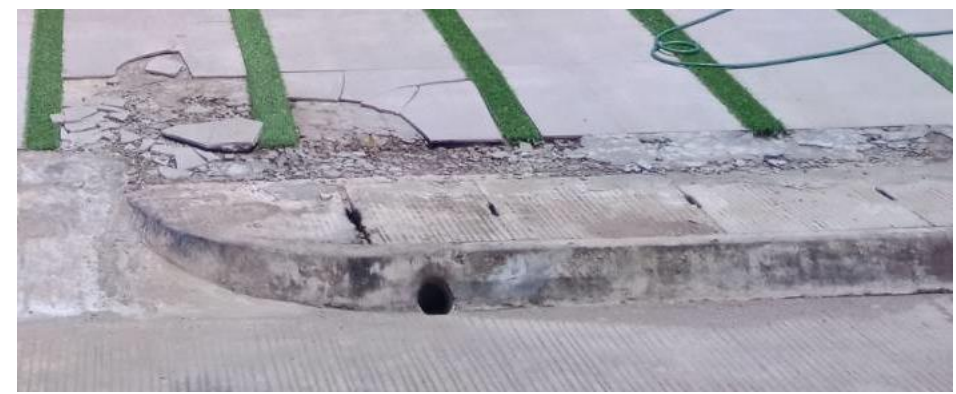

Gambar 6. Riol kota

Sumber: Pribadi

Jaringan Sampah

Sampah di cluster Tropical valley menggunakan system kolektif yang di letakan di depan rumah menggunakan kotak sampah masing-masing yang telah disiapkan dan akan di angkut oleh DKK (Dinas Kebersihan Kota) setiap hari jam 10.00 WIB

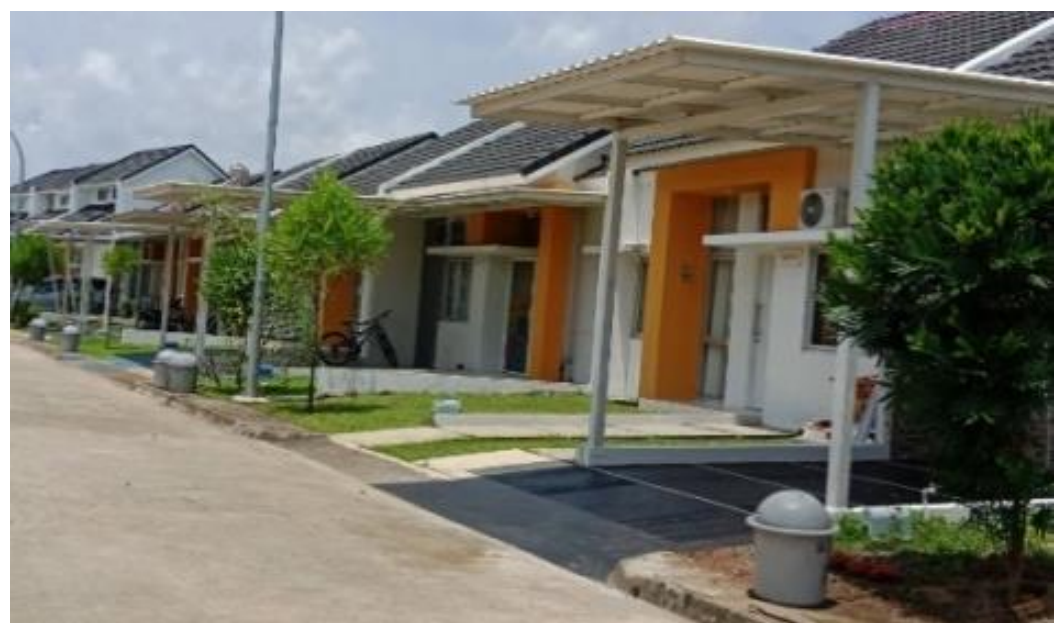

Gambar 7. Bak sampah di depan rumah

Sumber: Pribadi 
Lebar jalan

Lebar jalan yang digunakan pada cluster Tropical Valley selebar 5m pada jalan tersebut

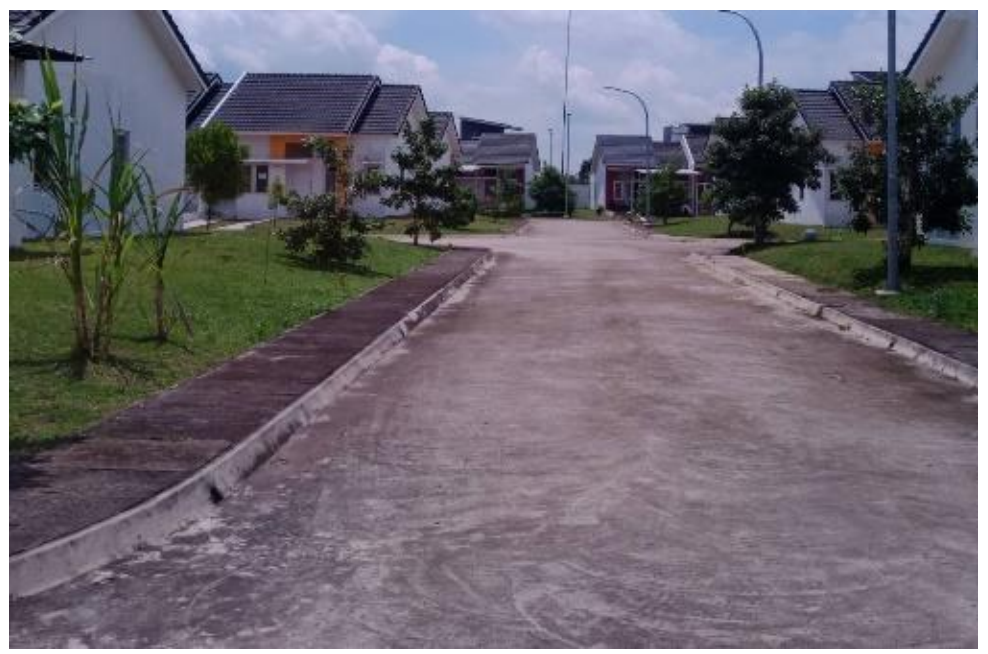

Gambar 8. Lebar jalan di Tropical Valley

Sumber: Pribadi

\subsection{Pembahasan Autumn Forest}

Autumn Forest merupakan salah satu bentuk realisasi program EcoCulture (Konsep pembangunan berwawasan lingkungan). Citra Grand City sudah menerapkan metode dan upaya untuk menjaga lingkungan agar tetap berkesinambungan melalui konsep EcoHome. EcoHome ini merupakan konsep hunian sehat berwawasan lingkungan yang diterapkan disemua sudut pengembangan CitraGrand City. Semua hunian yang dibangun oleh CitraGrand City adalah EcoHome yang merupakan hunian sehat yang berwawasan lingkungan dan salah satunya ini adalah hunian di Cluster Autumn Forest yang terletak di Tahap II Pembangunan CitraGrand City.

\section{Jenis-jenis rumah pada Autumn Forest}

Autumn Forest merupakan lingkungan yang berisikan empat jenis cluster bergaya modern classic. Empat jenis cluster ini adalah orange maple, red cedar, yellow amber dan neo red cedar. Berikut merupakan luas dan gambar cluster tersebut.

\section{Pola Site Plan menghadap Utara-Selatan}

Dari sistem pola siteplan, orientasi penempatan arah muka bangunan rumah di Cluster Autumn Forest ini dirancang menghadap Utara - Selatan, yang bertujuan untuk mengurangi radiasi sinar matahari di pagi dan sore hari. Pola ini terbukti efektif dikarenakan pada siang hari pemilik rumah tidak akan merasakan panas sinar matahari yang berlebihan.

\section{Penyediaan Taman Depan dan Belakang pada Setiap Hunian}

Penyediaan $40 \%$ lahan terbuka hijau berupa taman depan dan belakang bagi para penghuni sebagai tempat untuk berekreasi atau bersosialisasi bersama keluarga. Kawasan dengan lahan terbuka hijau ini juga sangat baik bagi pernafasan karena mengandung lebih banyak oksigen.

\section{Fasilitas Umum \& Penunjang}

Selain dari jenis rumah cluster ini dilengkapi juga dengan fasilitas-fasilitas penunjang seperti :

Gerbang Cluster

Gerbang cluster menggunakan jenis portal, dan arus keluar masuk dalam perumahan ini di lakukan dengan satu jalur. 


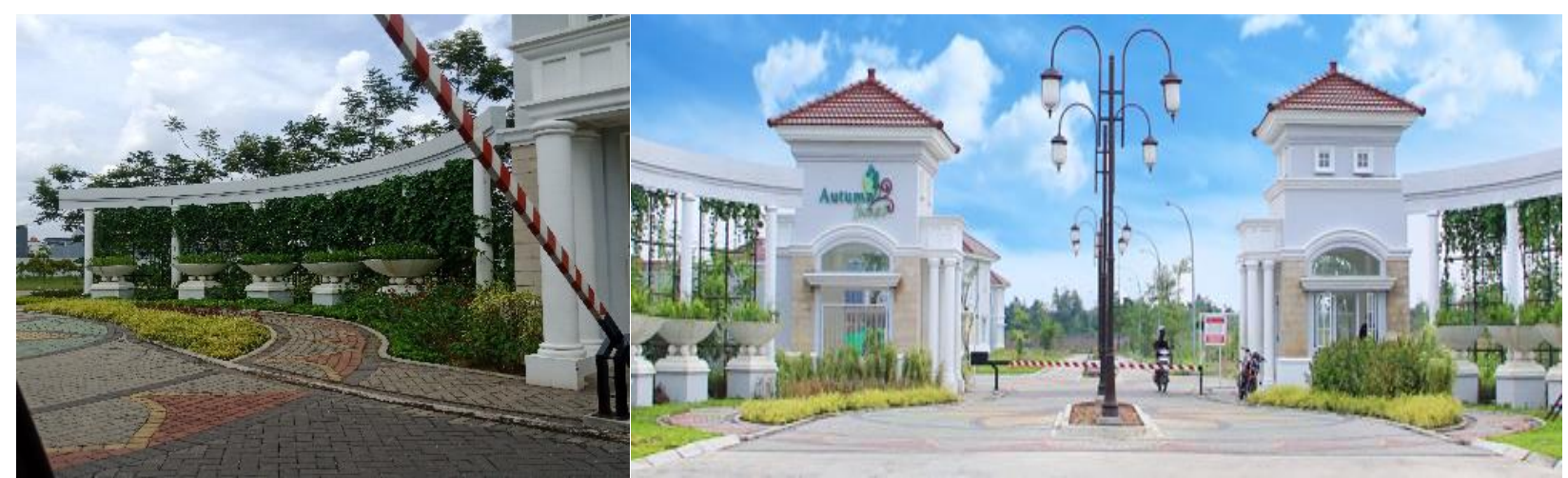

Gambar 9. Gerbang Cluster Autumn Forest

Sumber: Pribadi

Jaringan Listrik

Jaringan listrik di dalam perumahan Tropical Valley menggunakan sistem tanam di dalam tanah. Gardu listrik berada diluar site cluster, kemudian dari gardu listrik baru di alirakan ke rumah masing-masing

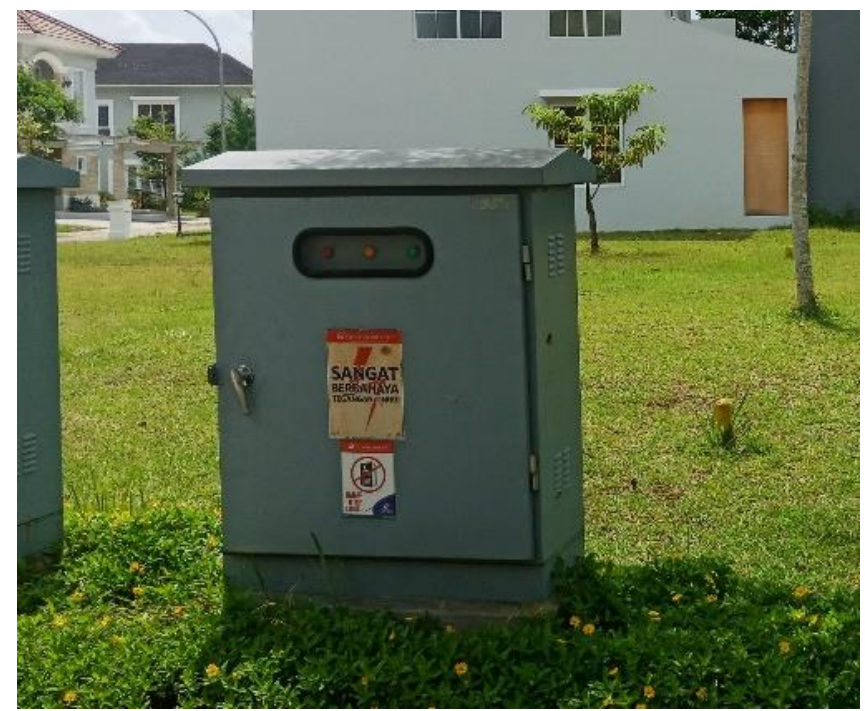

Gambar 10. Electric panel di cluster

Sumber: Pribadi

Di dalam cluster ini dilengkapi dengan genset sebagai tenaga cadangan dalam keadaan listrik padam.

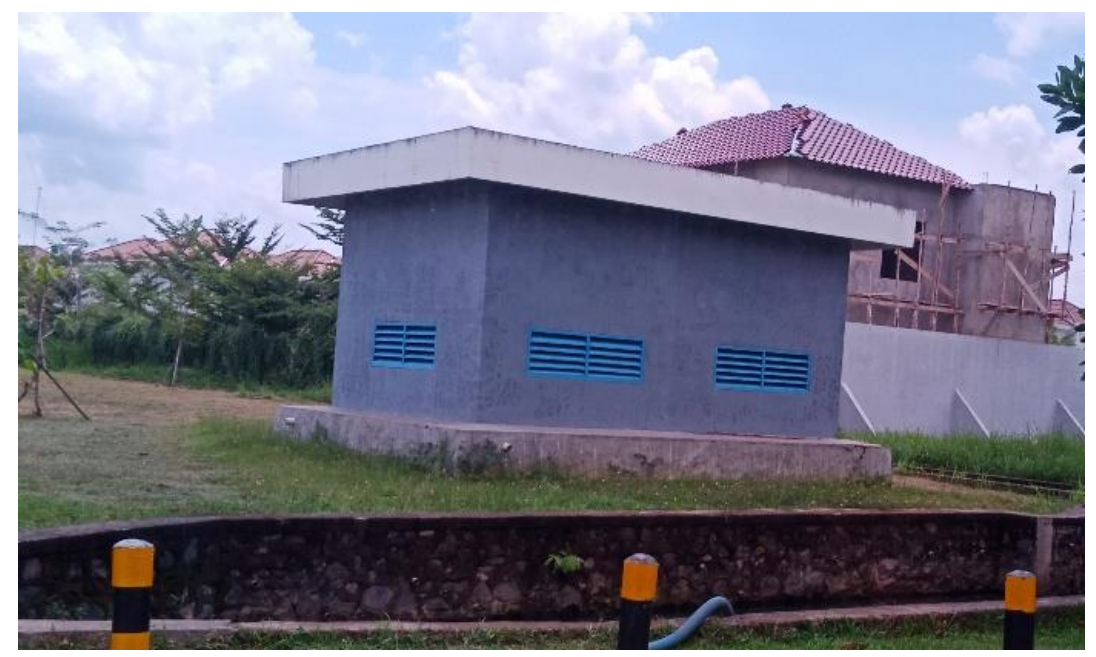

Gambar 11. Ruang genset di Autumn Forest

Sumber: Pribadi 
Jaringan Air Bersih

Penyediaan air bersih di dalam cluster Autumn Forest menggunakan air dari PDAM

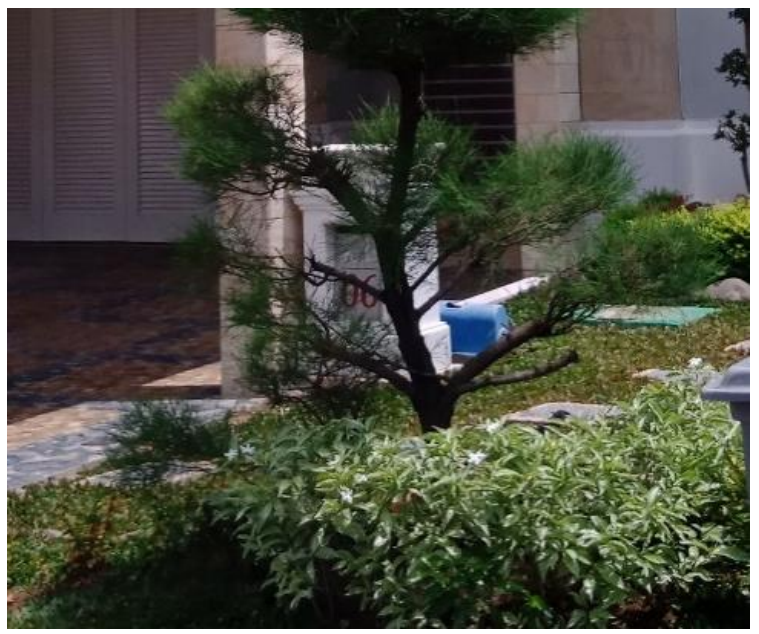

Gambar 12. Meteran PDAM

Jaringan Air Kotor

Sumber: Pribadi

Jaringan air kotor yang ada di cluster Autumn Forest menggunakan riol kota disepanjang tepi jalan depan halaman rumah.

Jaringan Sampah

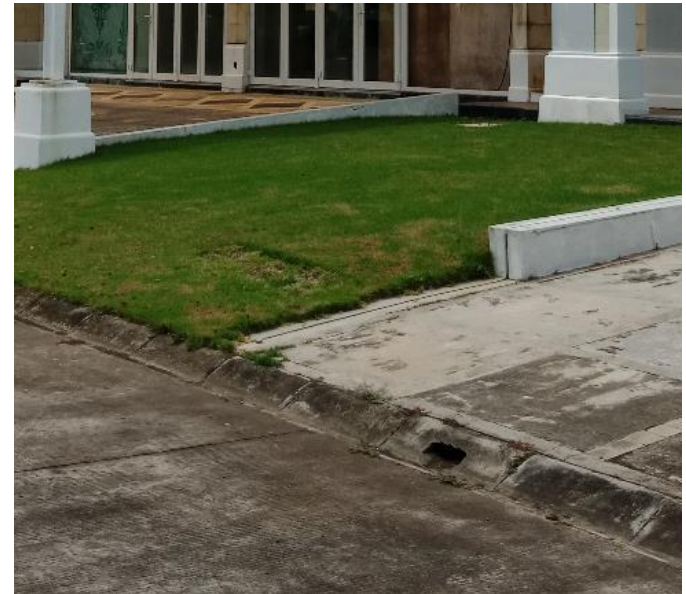

Gambar 13. Riol kota

Sumber: Pribadi

Sampah di cluster Autumn Forest menggunakan sistem kolektif yang di letakan di depan rumah menggunakan kotak sampah khusus yang telah disediakan di masing-masing rumah dan akan di angkut oleh DKK (Dinas Kebersihan Kota) setiap hari jam 10.00 WIB

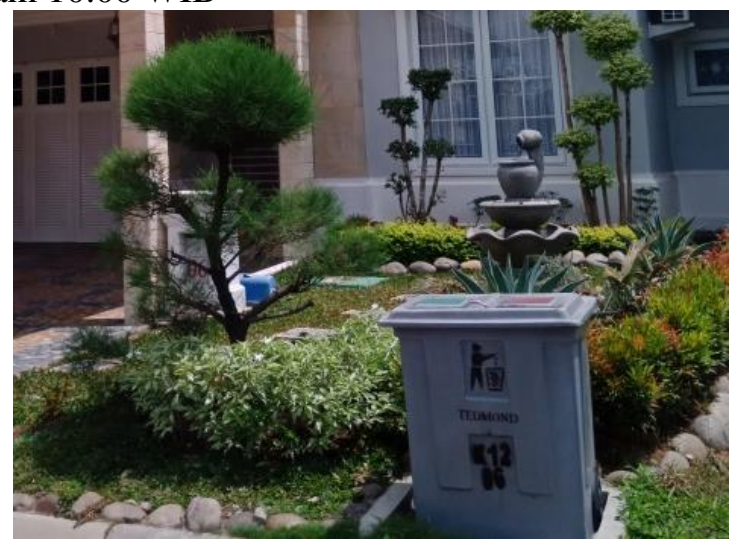

Gambar 14. Bak sampah di depan rumah

Sumber: Pribadi 


\section{Lebar jalan}

Lebar jalan yang digunakan pada cluster Autumn Forest selebar 6m pada jalan tersebut

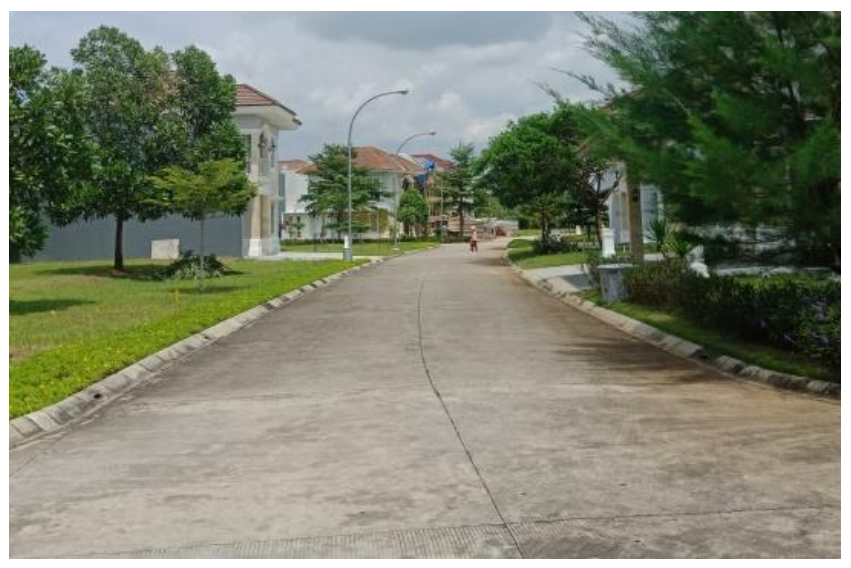

Gambar 15. Lebar jalan di Autumn Forest

Sumber: Pribadi

Kantong Parkir

Cluster Autumn Forest menyediakan fasilitas kantong parkir yang berada di luar site cluster dimana bisa menampung \pm 30 mobil. Jarak sekitar \pm 100 m menuju gerbang cluster Autumn Forest.

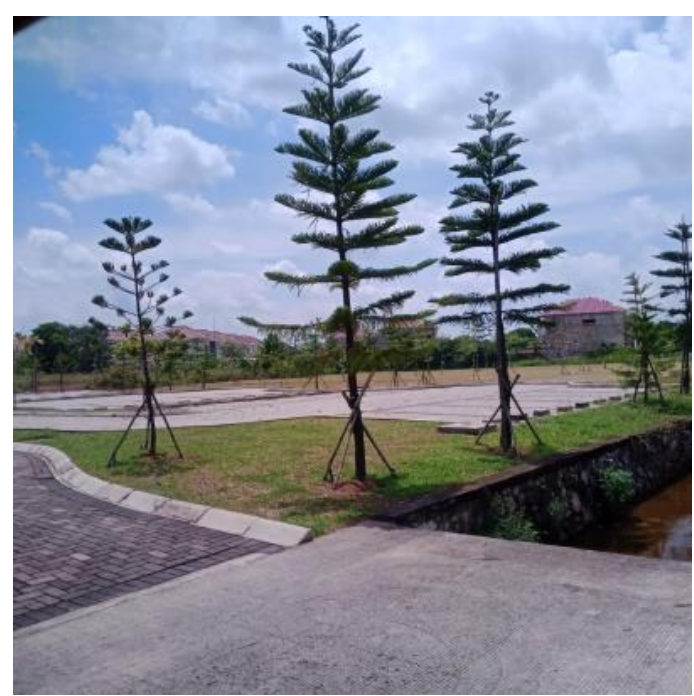

Gambar 16. Kantong Parkir diarea Autumn Forest

Sumber: Pribadi

\subsection{Konsep Pengembangan Perumahan Kompleks}

Dengan konsep Eco Culture, CitraGrand City menyajikan beraneka ragam tipe rumah cantik yang dapat dijangkau oleh seluruh kalangan, mulai dari harga Rp 300 jutaan hingga Rp 4 miliaran, yang ditata secara sempurna di dalam cluster tertutup dengan sistem single gate cluster dan underground infrastructure untuk keamanan, ketertiban serta kenyamanan yang optimal. Setiap cluster yang dibangun, selalu mengutamakan aspek penataan lanskap yang berfungsi sebagai penyeimbang ekologi, memberikan keteduhan, mempercantik lingkungan dan memberikan kualitas udara yang lebih sehat. Desain rumah, ruko dan bangunan komersial lainnya, telah dipikirkan secara cermat dan matang, agar senantiasa tampil cantik, prestige dan up-todate.Kekuatan desain telah menjadi daya tarik kuat bagi para konsumen yang membeli dan memilih untuk tinggal di CGCP.

CitraGrand City dikembangkan menjadi sebuah kawasan berkonsep New Township Development pertama di Palembang. CitraGrand City akan menjadi sebuah kota baru berkualitas tinggi yang dapat mendukung penghuninya hidup dan berkembang dengan baik sehingga segala potensi diri yang ada saat ini dapat dimanfaatkan secara maksimal untuk mewujudkan impian di masa depan. 
Di atas lahan seluas 250 hektar, ribuan hunian yang memberikan kenyamanan prima akan berdiri di Citra Grand City. Sementara berbagai fasilitas penunjang yang ada membuat hidup penghuni Citra Grand City menjadi mudah dan menyenangkan. Semuanya berpadu harmonis dalam gerak pembangunan berkelanjutan (sustainable development) dengan lingkungan hidup yang tertata dengan baik, hijau dan sehat. Kehidupan yang akan datang sangat ditentukan saat ini

Sejak dibangun pada tahun 2008, jumlah hunian, ruang komersial, dan fasilitasnya terus bertambah. Sampai saat ini, di Citra Grand City sudah terbangun hunian dan ruang komersial sebanyak 1.000 unit, dengan tingkat hunian mencapai $60 \%$. Sementara fasilitas yang sudah terbangun, antara lain

1. Amanzi Waterpark

2. Family Club (Ballroom, Kolam Renang, Lapangan Tenis, Tennis Meja, dan Gym)

3. Private Club House (Kolam Renang anak \& dewasa dan Gym)

4. Nasional Plus School by Ignatius Global School (IGS)

5. Commercial Area \& Food Area

6. Sarana Beribadah seperti Masjid

7. EcoPark (Danau buatan yang di dalamnya terdapat driving range, sarana outbond, jogging track dan lain-lain)

Citra Grand City dirancang sebagai kota yang memiliki aksesibilitas yang baik. Untuk itu saat ini sedang dilakukan penyelesaian jalan boulevard untuk tembus ke Jalan Soekarno Hatta. Penyelesaian jalan boulevard hingga tembus ke jalan Soekarno Hatta akan memberikan akses yang sangat mudah bagi penghuni dan pelaku usaha di kawasan Citra Grand City. Nantinya untuk menuju keluar dari kawasan ini tidak perlu memutar melalui Jalan Alang-Alang Lebar tetapi bisa melalui jalan boulevard yang tembus ini menuju ke jalan Soekarno Hatta dan terus ke wilayah lain.

Keunggulan proyek CGCP yang menjadi selling point sekaligus daya tarik bagi masyarakat di Sumatera Selatan adalah sebagai berikut :

1. CGCP hadir dan menjadi pioneer di kota Palembang, sebagai jawaban atas kebutuhan living and working space yang lebih nyaman, teratur, sehat, berwawasan lingkungan, memiliki infrastruktur dan fasilitas serta gaya hidup (life style) berstandar internasional.

2. Direncanakan dan dibangun oleh Ciputra Group yang selalu menjadi 5 besar pengembang property paling berprestasi dan bergengsi di Indonesia, dengan jumlah proyek lebih dari 70 lokasi hingga ke manca negara.

3. Talang Kelapa yang merupakan wilayah terbaik untuk dijadikan wilayah kota mandiri baru, dimana berdasarkan program nasional RI 2006, wilayah Talang Kelapa terpilih sebagai satu dari 8 lokasi terbaik Kasiba (Kawasan Siap Bangun) di Indonesia karena dari segi geografis wilayahnya lebih tinggi, infrastruktur yang mapan dan kemudahan aksesbilitas.

4. CGCP bukan sekedar membangun perumahan saja, tapi membangun suatu perkotaan yang mandiri, berstandar internasional dan berwawasan lingkungan, dengan kelengkapan 5 unsur pembentuk kota, yaitu : residential, business \& commercial, entertainment \& lifestyle center, infrastructure dan public/social facilities, yang dirancang oleh konsultan masterplan kelas dunia, yaitu Townland International yang berpusat di London.

5. Positioning Citra Grand City Palembang dapat disamakan seperti wilayah Pondok Indah, di Jakarta Selatan, yang merupakan kawasan perumahan paling bergengsi di Ibu kota; Citra Grand City Palembang juga menjadi masterpiece hunian di Palembang yang menjadi magnet tempat berkumpulnya masyarakat high end Sumatera Selatan dan lebih jauh menjadi simbol supremasi hunian di Palembang, dimana orang-orang yang tinggal di sini otomatis memiliki prestige tersendiri.

6. CGCP terletak sangat strategis, berada di ibu kota provinsi (Palembang), tepat di wilayah yang dikhususkan untuk pengembangan kota baru (Sunrise property project) dan dilintasi jalan by-pas dari Lampung menuju Jambi.

7. Kemudahan akses menuju bandara internasional Sultan Mahmud Badaruddin II yang dapat ditempuh hanya dalam waktu 10-15 menit.

8. Bagi para konsumen dari luar Sumatera Selatan, CGCP berada di kota Palembang yang telah menjadi kota terbesar ke-2 di Sumatera, masuk kategori 10 kota besar paling layak huni di Indonesia, hanya berjarak 50 menitan dari kota Jakarta dan memiliki akses langsung ke luar negeri.

9. Infrastruktur kota dibangun dengan standar internasional, bermutu tinggi untuk durability jangka panjang; seluruh badan jalan menggunakan material beton berkualitas tinggi dan seluruh jaringan utilitas serta drainase tertutup rapih di bawah tanah. 
10. Layanan purna jual yang handal dan professional, dengan menghadirkan Customer Care Center, Posko Layanan Gangguan 24 Jam di sepanjang tahun serta adanya program-program hospitality yang proaktif diselenggarakan bagi para konsumen yang menjadi warga di CGCP.

11. Rumah dan bangunan lainnya tidak dirancang secara sembarang, namun dilakukan secara cermat dan penuh cita rasa untuk memberikan added value/property selling point yang bernilai tinggi.

12. Diterapkannya program EcoCulture yang memberikan nilai manfaat yang sangat besar bagi kualitas hidup warga CGCP di setiap harinya dengan menerapkan aspek perencanaan, pembangunan hingga prilaku/gaya hidup berwawasan lingkungan dan berkelanjutan (suistanability).

13. Untuk menjaga keseimbangan ekosistem kota, seluas lebih dari 50 hektar kawasan di Citra Grand City disiapkan khusus sebagai ruang terbuka hijau (RTH) berupa taman lingkungan, green belt, children play ground, taman kota dan sejenisnya.

14. CGCP menyediakan lahan secara khusus dengan luas mencapai 15 hektar, untuk pembangunan proyek EcoPark, berupa danau dan taman yang menjadi 'jantung serta paru-paru' kota CGCP sekaligus kawasan rekreasi, resapan air dan pengendali banjir.

\section{Kesimpulan}

Diterapkannya program Eco Culture yang memberikan nilai manfaat yang sangat besar bagi kualitas hidup warga di kompleks perumahan Citra Grand City Palembang di setiap harinya dengan menerapkan aspek perencanaan, pembangunan hingga secara tidak langsung memberikan dampak perilaku/gaya hidup berwawasan lingkungan dan berkelanjutan (suistanability).

Fasilitas parkir selain diletakkan di halaman dari masing-masing rumah, juga direncanakan membuat kantong-kantong parkir pada lahan-lahan yang memang secara khusus disiapkan sebagai area parkir. Sistem pengelolaan sampah dilakukan oleh pihak manajemen perumahan.

Perubahan Fasad bangunan diperbolehkan sepanjang tidak mengubah jauh dari desain lingkungan sekitar.

\section{Referensi}

Anonimus, 1983, Pedoman Perencanaan Lingkungan Perumahan. Yayasan Badan Penerbit Pekerjaan Umum, Jakarta.

Hamzah, Andi, 2000, Syarat-syarat Sarana dan Prasarana yang Harus Dipenuhi dalam Pembangunan Rumah Susun

Hamzah F. Rahman, 2010, Kajian Pola Spasial Pertumbuhan Kawasan Perumahan dan Permukiman di Kecamatan Limboto Kabupaten Gorontalo, Program Studi Magister Teknik Pembangunan Wilayah dan Kota, Universitas Diponegoro Semarang

Haryadi, B. Setiawan, 2010, Arsitektur Lingkungan dan Perilaku, Suatu Pengantar ke Teori, Metodologi, dan Aplikasi, Gadjah mada University Press, Jogyakarta

Hasan, M. Iqbal, 2002, Pokok-pokok Materi Metodologi Penelitian dan Aplikasinya, Ghalia Indonesia, Bogor

Laurens, Joyce Marcella. 2004. Arsitektur dan Perilaku Manusia, Grasindo, Jakarta.

Muhammad Afdi Nizar, 2015, Kelas Menengah (Middle class) dan Implikasinya bagi Perekonomian Indonesia. https://researchgate.net/publication/279406954

Nadiar, F., Azmi, D., dan Nusantara, D. (2019). Arsitektur Mediterania Di Indonesia : Adaptasi Kemegahan Dan Kinerja Termal Bangunan Dari Daerah Mediterania Dalam. 2, 175-182.

Pindo Tutuko, 2008, Permukiman. Universitas Merdeka Malang.

Susanti, I. S., Komala Dewi, N. I., dan Permana, A. Y. (2018). Tatanan Teritorial dalam Proses Transformasi Hunian. Jurnal Arsitektur ZONASI, 1(1), 27. https://doi.org/10.17509/jaz.v1i1.11542

Yudohusodo, S., 1991, Rumah Untuk Seluruh Rakyat, INKOPPOL, Unit Percetakan Bharakerta, Jakarta 